\title{
Impact of Tobacco Addiction on Mean Visual Reaction Time of School Bus Drivers
}

\author{
Garima Shah ${ }^{1}$, Rajni Soni ${ }^{2}$, Manjula Mehta ${ }^{3}$ \\ ${ }^{1}$ Department of Physiology, SAIMS, Indore, Madhya Pradesh, India. 2Department of Physiology, MGM Medical College, \\ Indore, Madhya Pradesh, India. ${ }^{3}$ Department of Physiology, MGM Medical College, Indore, Madhya Pradesh, India.
}

\section{ABSTRACT}

\section{BACKGROUND}

Visual reaction time is a reliable indicator to assess the processing capability of central nervous system and sensory motor performance in response to an external stimulus. The present study aimed to assess the impact of tobacco addiction on mean visual reaction time among school bus drivers.

\section{METHODS}

A total of 100 male drivers were recruited, of which 74 were non-addicts who served as the control group and 26 were addicts. Background data was recorded using questionnaire and the visual reaction time was recorded for the two groups and compared.

\section{RESULTS}

The observations revealed that the visual reaction time was delayed in tobacco addicts as compared to that in controls.

\section{CONCLUSIONS}

The authors concluded that tobacco addiction may pose a threat as delayed visual reaction time may lead to road traffic accidents.

\section{KEY WORDS}

Tobacco, Reaction Time, Drivers
Corresponding Author:

Dr. Manjula Mehta,

Assistant Professor,

Department of Physiology,

MGM Medical College,

Indore, Madhya Pradesh, India.

E-mail: drmanjulamehta@hotmail.com

DOI: $10.14260 /$ jemds/2019/865

Financial or Other Competing Interests: None.

How to Cite This Article:

Shah G, Soni R, Mehta M. Impact of tobacco addiction on mean visual reaction time of school bus drivers. J. Evolution Med. Dent. Sci. 2019;8(52):4002-4004, DOI: 10. $14260 /$ jemds/2019/865

Submission 02-11-2019,

Peer Review 10-12-2019,

Acceptance 17-12-2019,

Published 30-12-2019. 


\section{BACKGROUND}

Reaction time is defined as an interval of time between the application of stimulus and the initiation of appropriate voluntary response under the condition that the subject has been instructed to respond as rapidly as possible. [1] Thus, it indicates the time taken by an individual to react to external stimulus. [2] Reaction time may be considered as an indirect index of the integrity and processing ability of the central nervous system. It remains to be a simple, non-invasive means of determining sensory-motor co-ordination and performance of an individual. [3,4]-A part of population wherein the visual reaction time holds utmost importance is that of drivers. Having a low reaction time while applying brakes, or in quick manoeuvring, may turn out to be life- saving for both the driver and passengers. But there may be several factors, internal as well as external, which may affect the visual reaction time in drivers. One such factor is tobacco addiction.

The prevalence of tobacco addiction in India is very high. With an increasing use of both smoking and smokeless forms of tobacco, the prevalence of its use varies from 7-60\% between the states. It has been found that the commonest form of tobacco used by drivers is Gutka. The habit is initiated among them as early as 15 years of age, peer pressure and work stress being the most common cause for the same. High knowledge and awareness do not discourage them from quitting the habit. [5] Tobacco use has been often associated with negative effects on several cognitive functions. One form of cognition, which serves as a powerful means to assess the integration of sensory, motor and coordination system of the body in response to an external stimulus is the reaction time. [6]

Thus, the present study was conducted with the objective of comparing the visual reaction time of bus drivers who are tobacco addicts, to the control non- addict bus drivers. The hypothesis was that the reaction time of addicts may be delayed as compared to the non-addicts.

\section{METHODS}

A cross- sectional study was conducted in the Department of Physiology, Mahatma Gandhi Memorial Medical College, Indore (M.P. ). The study population consisted of school bus drivers. Purposive sampling was carried out by the primary investigator. Sample size was calculated using data from previous studies considering $\mathrm{p}<0.05$ as acceptable with a power of $80 \%$ and the following sample size formula

$\mathrm{n}=2(\mathrm{Za}+\mathrm{Z} 1-\beta) 2 \sigma 2 / \Delta 2$

was used for the same, deriving a sample size of 100. [7] School bus drivers, meeting the inclusion criteria, who gave their oral and written informed consent to participate in the study, were recruited. Ethical approval was obtained from Ethics and Scientific Review Committee M. G. M. Medical College M. Y. Hospital, Indore. Inclusion criteria were school bus drivers of age group 20-50 years, healthy males, driving the vehicle for more than one year, having no auditory or visual disturbances and those who are not taking any sedative or hypnotic or anti-allergic medicine.

\section{Recording the Reaction Time}

A standardized -608 audio- visual reaction timer instrument was used in this study. Three practical trials were given before taking the observation. Before presenting a stimulus, a ready signal or warning in the form of a verbal instruction READY was given. The subjects sat to one side and examiner sat to other side of instrument. When the examiner pressed the switch, visual stimuli appeared on screen which is in front of the subjects. Subject had to react to three different colours of light i.e. red, green and yellow by pressing the respective key for the colour as soon as that respective colour is presented on the screen. The time of pressing the key was directly taken as visual reaction time. Three practical trials of visual stimuli were given to each subject and the best (i.e. the lowest) was taken as the visual reaction time of that subject.

\section{Recording Data on Tobacco Addiction}

Self-designed questionnaires were used consisting of questions regarding the demographic data (name, age) of the subjects and their tobacco- related habits (type, duration, frequency, quantity). On evaluation by subject experts, the questionnaire was found to be valid. The test- retest reliability measure was used to test the consistency of the questionnaire. Before the start of the study, the questionnaire was administered to a set of 15 school bus drivers at random, twice at an interval of 10 days. The co- relation co- efficient was found to be 0.84 .

\section{Statistical Analysis}

The data for 100 drivers was tabulated and then divided into two groups- tobacco addicts and non-addicts, based on the questionnaire analysis. The mean visual reaction time was calculated for both the groups. Comparison for the same between the two groups was carried out using the unpaired $t$ test. These 100 drivers were divided into 2 groups based on their tobacco addiction. Group 1 consisted of 26 drivers who were tobacco addicts and group 2 had 74 non-addict drivers. The compatibility between the two groups was found using the unpaired t- test. $\mathrm{P}$ value was $0.075(>0.05)$, which revealed that the difference between the two was non significant. Thus, the two groups were found to be comparable for further analysis.

\section{RESULTS}

The mean age of the bus drivers was $39.7 \pm 6.79$ years. Of the 100 drivers recruited in the study, 26 were tobacco addicts, while 74 were non-addicts. Mean visual reaction time was compared between the two groups for red, green and yellow colour. It was seen that the difference in reaction time was statistically significant between addicts and non-addicts, specifically for red colour $(\mathrm{p}<0.05)$. (Table 1)

\begin{tabular}{|c|c|c|c|c|}
\hline $\begin{array}{c}\text { Visual } \\
\text { Reaction Time }\end{array}$ & $\begin{array}{c}\text { Non- } \\
\text { Addicts (n=74) } \\
{[\text { Mean } \pm \text { SD] }}\end{array}$ & $\begin{array}{c}\text { Addicts } \\
\text { (n=26) } \\
{[\text { Mean } \pm \text { SD] }]}\end{array}$ & $\begin{array}{c}\text { 't' } \\
\text { Value }\end{array}$ & p \\
\hline Red colour & $0.85 \pm 0.28$ & $0.99 \pm 0.29$ & -2.240, & $0.027^{*}$ \\
\hline Green colour & $0.84 \pm 0.32$ & $0.96 \pm 0.35$ & -1.700 & $0.092, \mathrm{NS}$ \\
\hline Yellow colour & $1.02 \pm 1.24$ & $0.97 \pm 0.26$ & 0.208 & $0.836, \mathrm{NS}$ \\
\hline \multicolumn{5}{|c|}{ Table 1. Comparison of Mean Visual Reaction Time between } \\
Addicts and Non-Addicts \\
\hline *Statistically Significant
\end{tabular}




\section{DISCUSSION}

The present study focused on the mean visual reaction time of school bus drivers and one of the important variables associated with it, that is, tobacco addiction. The main reason for the same is that, if we could establish factors responsible for prolonging reaction time in such professionals, further work can be done in eliminating these factors, thereby reducing the number of road traffic accidents. Tobacco has a high nicotine content. It has been found that, in small amounts, nicotine has a stimulatory effect and hence, a positive effect on reaction time. On the other hand, when consumed in large amounts, as in the case of tobacco addicts, it exerts a negative effect on the reaction time. ${ }^{[8]}$ In our study, when compared to the non - addicts, we found that tobacco addicts had a prolonged visual reaction time. These results are in line with the findings by Ichaporia $\mathrm{RB}$ et al, [9] who conducted a similar study in 50 smokers. When smoked in small number, a reduction in visual reaction time was noted, due to the arousal effects of nicotine; but visual reaction time was increased in individuals who had a higher frequency of cigarette smoking.

Vijaykumar and Badiger[10] studied the effect of both acute as well as chronic nicotine consumption on reaction time. As opposed to the results of our study, they found that both acute and chronic smokers had a lower reaction time as compared to 66 non- smokers. They concluded that this was because nicotine improved cognition in smokers. On the other hand, Jadhao $\mathrm{P}$ et al[6] in their study found that the visual reaction time was delayed in chronic smokers as compared to non- smokers. This delay was attributed to the impaired perceptual- motor coordination in chronic smokers. The present study evaluated tobacco as a factor delaying visual reaction time which is statistically significant for red colour. But there are several other factors which may also contribute along with tobacco. Hence, there is need of a larger, extensive study taking into consideration other variables, and the co-relation between them.

\section{CONCLUSIONS}

Tobacco addiction causes a delay in visual reaction time as compared to the non-addicts. Owing to this, even simple tasks can become challenging over a period of time. Hence, tobacco addiction may pose as a significant threat in the context of bus drivers, as delayed reaction times may lead to road traffic accidents. Hence, creating awareness and establishing rehabilitation centres for the said population will serve as a big step in contributing towards community health and preventive medicine.

\section{REFERENCES}

[1] Teichner WH. Recent studies of simple reaction time. Psychol Bull 1954;51 (2:1) :128-49.

[2] Mishra N, Mahajan KK, Maini BK. Comparative study of visual and auditory reaction time of hands and feet in males and females. Ind J Physiol Pharmacol 1985;29 (4) :213-8.

[3] Lofthus GK. Sensory motor performance and limb preference. Percepts Motor Skills 1981;52 (3) :68893.

[4] Das S, Gandhi A, Mondal S. Effect of premenstrual stress on audiovisual react ion time and audiogram. Ind J Physio Pharmacol 1997;41 (1) :67-70.

[5] Parashari A, Ahmad S, Asthana S, et al. Tobacco use among drivers and conductors in Western Uttar Pradesh, India. Indian Journal of Community Health 2017;29 (3) :301-7.

[6] Jadhao PS, Kamble P, Deshpande VK, et al. The study of auditory and visual reaction times in chronic smokers. Int J Med Health Sci 2013;2 (1) :18-22.

[7] Kadam P, Bhalerao S. Sample size calculation. Int J Ayurveda Res 2010;1 (1) :55-7.

[8] Wahome EN. Effects of smoking on visual and auditory reaction time. Kenyatta University Institutional Repository, 1997. http://ir-library. ku. ac. ke/handle/123456789/13739

[9] Ichaporia RB, Kulkarni SP, Malthi A, et al. Study of reaction time in smokers. Journal of Postgraduate Medicine 1991;37 (4) :209-10.

[10] Vijaykumar N, Badiger S. Effect of acute and chronic nicotine consumption on reaction time. Al Ameen J Med Sci 2015;8 (3) :179-83. 